\title{
LATIHAN HIGH-INTENSITY INTERVAL TRAINING RASIO WORK-TO- REST 2:1 SAMA BAIKNYA DENGAN 1:1 DALAM MENINGKATKAN DAYA TAHAN KARDIORESPIRASI PADA PELARI KOMUNITAS
}

\section{Leandra Erdina Usmany ${ }^{1}$, I Made Krisna Dinata ${ }^{2}$, S. Indra Lesmana ${ }^{3}$, J.Alex Pangkahila ${ }^{4}$, Luh Made Indah Sri Handari Adiputra², I Putu Adiartha Griadhi}

\author{
${ }^{1}$ Program Studi Magister Fisiologi Keolahragaan Universitas Udayana, Denpasar \\ ${ }^{2}$ Departemen Ilmu Faal, Fakultas Kedokteran Universitas Udayana, Denpasar \\ ${ }^{3}$ Fakultas Fisioterapi Universitas Esa Unggul, Jakarta \\ ${ }^{4}$ Departemen Andrologi, Fakultas Kedokteran Universitas Udayana, Denpasar
}

Email: leandraerdina@ymail.com

\begin{abstract}
ABSTRAK
Pendahuluan: Performa seorang pelari dipengaruhi oleh beberapa faktor, salah satunya daya tahan kardiorespirasi. High-intensity interval training (HIIT) telah diusulkan sebagai strategi latihan yang menghemat waktu untuk meningkatkan daya tahan kardiorespirasi $\left(\mathrm{VO}_{2} \mathrm{max}\right)$. Tujuan penelitian ini untuk mengetahui perbandingan pengaruh HIIT rasio work-to-rest 2:1 dengan 1:1 dalam meningkatkan daya tahan kardiorespirasi pada pelari komunitas.

Metode: Penelitian ini bersifat eksperimental dengan rancangan berupa randomized pre and post test group design, teknik pengambilan sampel menggunakan consecutive sampling. Sampel penelitian berjumlah 22 orang usia 20-30 tahun. $\mathrm{VO}_{2}$ max diukur dengan menggunakan 1,5 mile run test / tes lari $2,4 \mathrm{~km}$.

Hasil: . Hasil analisis uji t tidak berpasangan setelah intervensi pada kedua kelompok diperoleh nilai $\mathrm{p}=0,579(\mathrm{p}>0,05)$ yang berarti tidak ada perbedaan yang bermakna pada intervensi HIIT rasio work-to-rest 2:1 dibandingkan dengan HIIT rasio work-to-rest 1:1 terhadap peningkatan daya tahan kardiorespirasi pada pelari komunitas.

Simpulan : HIIT 1:1 sama baiknya dengan 2:1 dalam meningkatkan daya tahan kardiorespirasi. Latihan HIIT dengan rasio work-to-rest 1:1 dan 2:1 dapat digunakan sebagai strategi latihan untuk meningkatkan daya tahan kardiorespirasi ( $\left.\mathrm{VO}_{2} \mathrm{max}\right)$.
\end{abstract}

Kata Kunci: High-intensity interval training, daya tahan kardiovaskular, pelari, 1,5 mile run test.

\section{HIGH-INTENSITY INTERVAL TRAINING WORK-TO-REST RATIO 2:1 AS GOOD AS 1:1 ON INCREASING CARDIORESPIRATION ENDURANCE IN RUNNERS COMMUNITIES}

\begin{abstract}
Background: A runner's performance affected by several factors, one of them is cardiorespiratory endurance. High-intensity interval training (HIIT) has been proposed as an exercise strategy that saves time to increase cardiorespiratory endurance ( $\left.\mathrm{VO}_{2} \mathrm{max}\right)$. This study aims to compare the effect of HIIT work-to-rest ratio 2:1 with 1:1 on increasing cardiorespiratory endurance in runners' communities.
\end{abstract}


Methods: This research is an experimental design of randomized pre and post test group design, the sampling techniques using a consecutive sampling. Sample consisted of 22 people aged 20-30 years. $\mathrm{VO}_{2}$ max was measured with 1,5 mile run test $/ 2,4 \mathrm{~km}$ run test.

Result: The results of independent t-test after intervention for both groups show that $\mathrm{p}$ value $=0.579$ ( $p>0,05)$ means no significant difference in intervention HIIT work-to-rest ratio 2:1 compared to HIIT work-to-rest ratio 1:1 on increasing cardiorespiratory endurance in runners' communities.

Conclusion: HIIT 1:1 is as good as 2:1 on increasing cardiorespiratory endurance. HIIT work-to-rest ratio of $1: 1$ and 2:1 can be used as an exercise strategy for increasing cardiorespiratory endurance $\left(\mathrm{VO}_{2} \max \right)$.

Keywords: High-intensity interval training, cardiovascular endurance, runners, 1,5 mile run test.

\section{PENDAHULUAN}

Dalam beberapa dekade terakhir, partisipasi event lari menjadi semakin populer bagi jutaan atlet non-profesional di seluruh dunia setiap tahun. Komunitas lari juga semakin banyak terbentuk di setiap kota, khususnya di Denpasar. Setiap pelari di sebuah komunitas memiliki targetnya masing-masing ketika mengikuti sebuah event lari. Menurut observasi lapangan yang peneliti lakukan terhadap suatu komunitas, kebanyakan pelari berpartisipasi dalam sebuah event dengan target agar mereka dapat mencapai finis dan adapun beberapa pelari yang memiliki target untuk personal best mereka yaitu dengan harapan mereka dapat lari dengan waktu dan pace yang lebih cepat.

Performa seorang pelari dipengaruhi oleh beberapa faktor, salah satunya daya tahan kardiorespirasi. Daya tahan kardiorespirasi merupakan unsur kebugaran jasmani yang sangat dibutuhkan oleh seorang pelari. Daya tahan kardiorespirasi merupakan kemampuan paru, jantung, dan pembuluh darah untuk membawa sejumlah oksigen dan nutrisi ke selsel untuk memenuhi kebutuhan aktivitas fisik yang berlangsung dalam waktu yang lama. Dalam hal ini $\mathrm{VO}_{2} \max$ (Volume oksigen maksimal) sebagai indikator dari daya tahan kardiorespirasi, apabila seseorang memiliki $\mathrm{VO}_{2}$ max yang tinggi maka daya tahan kardiorespirasi orang tersebut juga tinggi. ${ }^{1}$

Daya tahan kardiorespirasi tentu membutuhkan kapasitas aerobik yang memadai sesuai dengan performa masingmasing atlet. Latihan Aerobik yang intensif dan jangka panjang dapat meningkatkan kebutuhan oksigen pada otot rangka yang ditandai dengan peningkatan serapan oksigen pada paru-paru dan pasokan darah kaya akan oksigen ke otot rangka yang dilatih. Di bawah kondisi fisiologis, adaptasi kardiopulmonal sesaat meliputi peningkatan ventilasi paru, volume stroke, curah jantung disertai dengan peningkatan tingkat sedang dalam tekanan darah sistolik, vasokonstriksi dan vasodilatasi perifer, sehingga pada saat latihan aerobik, proses adaptasi jantung sesaat ini dapat dipertahankan hingga beberapa jam oleh jantung yang terlatih. ${ }^{2}$ Dalam ilmu dan praktis olahraga dan latihan, perhatian khusus telah diberikan untuk pengembangan strategi latihan dalam meningkatkan performa hubungannya dalam kualitas fisik.

High-intensity interval training (HIIT) telah diusulkan sebagai strategi latihan yang menghemat waktu untuk meningkatkan kekuatan aerobik $\left(\mathrm{VO}_{2} \max \right){ }^{3}$ Telah diketahui bahwa HIIT adalah modalitas yang bermakna dalam persiapan untuk kompetisi yang didominasi oleh oksigen (aerobik) misalnya lari jarak jauh / bersepeda dan oksigen independen jalur metabolisme (anaerobik) misalnya olahraga tim, lari sprint, dll. Manfaat dari HIIT yaitu dengan jarak latihan dan istirahat yang benar, pelari dapat menyelesaikan sejumlah besar latihan pada intensitas yang lebih tinggi yang biasanya tidak mungkin dilakukan dengan continuous running, yang di mana latihan continuous running diterapkan oleh sebagian besar komunitas menurut observasi di lapangan. Misalnya, jika pelari berusaha 
mempertahankan intensitas $90 \%$ hingga $100 \%$ HR selama mungkin, kelelahan akan muncul dalam beberapa menit dan intensitas latihan harus diturunkan. Namun, selama program interval, pelari dapat berlatih dengan intensitas tinggi selama beberapa waktu singkat, dengan jeda pemulihan di antaranya, yang memungkinkan total waktu yang dihabiskan pada intensitas tinggi lebih lama. ${ }^{4}$

Seiler dan Sjursen menyatakan bahwa ada banyak cara untuk memanipulasi model latihan interval untuk seorang atlet. Kebanyakan di antara variabel yang biasa dimanipulasi adalah durasi dan intensitas rest. Seperti yang diharapkan, ketika variabelvariabel ini dimanipulasi, mereka memanifestasikan berbagai tingkat kelelahan relatif terhadap respon fisiologis (heartrate, $\mathrm{VO}_{2}$ ) dan biokimia (laktat darah [La]) yang sebagaimana dibuktikan oleh perubahan dalam skala Ratings of Perceived Exertion (RPE). Untuk itu, ada kebutuhan yang berkelanjutan untuk memantau dampak manipulasi variabel pada respons individu selama latihan interval. ${ }^{5}$

Seiler dan Hetlelid menerbitkan sebuah studi baru yang merinci respons fisiologis dan persepsual untuk memanipulasi durasi pemulihan selama HIIT pada pria yang sangat terlatih. Dalam penelitian mereka, masingmasing subjek melakukan 3 sesi latihan HIIT menggunakan enam 4-menit interval dengan 1, 2, atau 4 menit pemulihan. Hasil dari penelitian tersebut menunjukkan bahwa rasio work-to-rest yang optimal adalah 2:1, karena menghasilkan intensitas latihan yang optimal dengan sedikit manfaat yang diperoleh dengan memberikan durasi rest tambahan. ${ }^{5}$

Adapun penelitian yang dilakukan oleh Gosselin pada tahun 2012 di mana membandingkan rasio work-to-rest 1:1, 2:1, 3:1 pada latihan interval aerobik yang menunjukkan bahwa rasio yang menghasilkan $\mathrm{VO}_{2}$, HR, RPE, dan laktat darah paling tinggi adalah 3:1 sedangkan 1:1 menunjukkan hasil parameter paling rendah. ${ }^{6}$ Sedangkan dalam sebuah tulisan di Rowing news magazine menyatakan bahwa selama latihan interval, periode durasi rest akan tergantung pada durasi dan intensitas periode latihan. Latihan interval akan bervariasi untuk rasio $1: 1$ hingga $1: 4$ untuk rest. Sebagai tambahan, sebuah penelitian juga dilakukan oleh Buchheit \& Laursen pada tahun 2013 rekomendasi untuk melakukan HIIT dengan long interval yaitu dengan rasio $1: 1 .^{7}$

Pemberian latihan harus memberikan kelebihan yang cukup untuk memaksimalkan performa dan meminimalkan kemungkinan atlet untuk cedera sehingga baik intensitas optimal dan durasi rest layak mendapat perhatian yang cukup. Dalam kompetisi olahraga, ada berbagai macam pola work-torest pada latihan interval yang semuanya terlibat dalam kemampuan untuk mempertahankan performa seoptimal mungkin. Namun, belum ada penelitian sebelumnya yang meneliti tentang pengaruh latihan interval dengan rasio work-to-rest 2:1 dan 1:1 pada pelari komunitas. Oleh karena itu, tujuan dari penelitian ini adalah untuk melihat perbandingan pengaruh pemberian latihan dan durasi rest terhadap peningkatan daya tahan kardiorespirasi pada pelari komunitas.

\section{METODE PENELITIAN}

Rancangan penelitian ini bersifat eksperimental dengan rancangan berupa randomized pre and post group design yang bertujuan untuk mengetahui perbandingan pengaruh High-intensity Interval Training Rasio Work-Rest 2:1 dengan 1: 1 terhadap Peningkatan Daya Tahan Kardiorespirasi pada Komunitas Pelari.

Penelitian untuk observasi, pre-test, post-test dan intervensi dilakukan di GOR Ngurah Rai Denpasar dan Lapangan Renon. Penelitian ini dilakukan selama tenggang waktu 6 minggu pada bulan Maret-Mei 2019.

Pada penelitian ini, pengambilan sampel pada pelari komunitas. Semua pelari yang memenuhi kriteria inklusi yaitu laki-laki dan berusia 20-30 tahun, dimasukkan dalam sampel penelitian sampai jumlah subjek yang diperlukan terpenuhi. Sampel berjumlah 22 orang, masing-masing kelompok terdiri dari 11 orang. Alat ukur yang digunakan untuk mengukur VO2max yaitu dengan 1,5 mile run test/ lari 2,4 km. 


\section{HASIL PENELITIAN}

\section{Karakteristik Subjek Penelitian}

Berdasarkan Tabel 1 menunjukkan hasil perhitungan uji beda dengan menggunakan uji beda, dari nilai rerata usia diperoleh nilai $p=0,559(p>0,05)$, dapat disimpulkan bahwa karakteristik usia pada kedua kelompok perlakuan tidak berbeda bermakna. Sedangkan nilai rerata IMT diperoleh nilai $\mathrm{p}=0,028(\mathrm{p}<0,05)$, yang berarti bahwa karakteristik IMT pada kedua kelompok perlakuan berbeda bermakna. Tabel 1.

Karakteristik Subjek Penelitian

\begin{tabular}{cccc}
\hline \multirow{2}{*}{$\begin{array}{c}\text { Karakte } \\
\text { ristik }\end{array}$} & \multicolumn{2}{c}{ Rerata } & \multirow{2}{*}{$\begin{array}{c}\text { Kelompok I } \\
\text { II }\end{array}$} \\
\hline Usia & $25,55 \pm 3,47$ & $24,73 \pm 2,97$ & 0,559 \\
\hline IMT & $24,55 \pm 1,14$ & $23,07 \pm 1,74$ & 0,028
\end{tabular}

\section{Uji Normalitas Data dan Homogenitas}

Berdasarkan Tabel 2 hasil uji normalitas distribusi data dengan menggunakan Saphiro wilk test didapatkan nilai probabilitas untuk kelompok data sebelum intervensi pada kelompok I, nilai $\mathrm{p}=0,933(\mathrm{p}>0,05)$ yang berarti bahwa data berdistribusi normal dan pada kelompok II, nilai $\mathrm{p}=0,149(\mathrm{p}>0,05)$ yang berarti bahwa data berdistribusi normal. Kelompok data setelah intervensi pada kelompok I, nilai $\mathrm{p}=0,391(\mathrm{p}>0,05)$ yang berarti bahwa data berdistribusi normal. Demikian juga dengan hasil analisis pada kelompok II, nilai $\mathrm{p}=0,689(\mathrm{p}>0,05)$ yang berarti bahwa data berdistribusi normal.

Tabel 2.

Uji Normalitas Data dan Homogenitas

\begin{tabular}{|c|c|c|c|}
\hline & \multicolumn{2}{|c|}{$\begin{array}{l}\text { Uji Normalitas } \\
\text { (Saphiro Wilk Test) }\end{array}$} & \multirow{2}{*}{$\begin{array}{l}\text { Uji } \\
\text { Homogenita } \\
\text { s } \\
\text { (Levene's } \\
\text { Test) } \\
\text { P }\end{array}$} \\
\hline & Kel. I & Kel. II & \\
\hline $\begin{array}{l}\text { Sebelum } \\
\text { intervensi }\end{array}$ & 0,933 & 0,149 & 0,162 \\
\hline $\begin{array}{l}\text { Setelah } \\
\text { intervensi }\end{array}$ & 0,391 & 0,689 & 0,338 \\
\hline
\end{tabular}

Tabel 2 juga menunjukkan hasil perhitungan uji homogenitas dengan menggunakan Levene's Test, dari data sebelum intervensi pada kelompok I dan kelompok II diperoleh nilai $\mathrm{p}=0,162(\mathrm{p}>0,05)$ sedangkan setelah intervensi diperoleh nilai $\mathrm{p}=0,338(\mathrm{p}$ $>0,05$ ). Dapat disimpulkan bahwa pada kedua kelompok perlakuan memiliki data homogen.

\section{Uji Komparasi Selisih Daya Tahan Kardiorespirasi Sebelum dan Setelah Intervensi pada Kedua Kelompok Penerapan}

Berdasarkan Tabel 3 hasil perhitungan beda rerata daya tahan kardiorespirasi sebelum intervensi diperoleh nilai $\mathrm{p}=0,127(\mathrm{p}>0,05)$, hal ini berarti tidak ada perbedaan yang bermakna pada intervensi kelompok I dibandingkan dengan kelompok II terhadap daya tahan kardiorespirasi pada pelari komunitas. Begitu pula pada hasil perhitungan beda rerata peningkatan daya tahan kardiorespirasi setelah intervensi, diperoleh nilai $p=0,579(p>0,05)$. Dapat disimpulkan bahwa intervensi kelompok I sama baiknya dengan kelompok II dalam meningkatkan daya tahan kardiorespirasi.

Tabel 3.

Hasil Uji Beda nilai $\mathrm{VO}_{2}$ max Sebelum dan Setelah Intervensi

\begin{tabular}{cccc}
\hline $\begin{array}{c}\text { Kelom } \\
\text { pok }\end{array}$ & $\begin{array}{c}\text { Sebelum } \\
\text { Intervensi }\end{array}$ & $\begin{array}{c}\text { Setelah } \\
\text { Intervensi }\end{array}$ & Nilai p \\
\hline I & $38,80 \pm 3,58$ & $43,17 \pm 3,42$ & 0,002 \\
II & $35,77 \pm 5,21$ & $42,22 \pm 4,10$ & 0,000 \\
Nilai p & 0,127 & 0,579 & - \\
\hline
\end{tabular}

\section{Uji Beda Rerata Peningkatan Daya Tahan Kardiorespirasi Sebelum dan Setelah Intervensi}

Berdasarkan Tabel 3 dilakukan pengujian hipotesis untuk mengetahui perbedaan peningkatan daya tahan kardiorespirasi sebelum dan setelah perlakuan pada Kelompok I, menggunakan uji beda yaitu 
paired sample t-test. Dari hasil perhitungan didapatkan nilai $\mathrm{p}=0,002(\mathrm{p}<0,05)$ yang berarti bahwa ada perbedaan yang bermakna dari peningkatan daya tahan kardiorespirasi sebelum dan setelah intervensi High-intensity Interval Training rasio work-to-rest $2: 1$ pada pelari komunitas.

Pengujian hipotesis untuk mengetahui perbedaan peningkatan daya tahan kardiorespirasi sebelum dan setelah perlakuan pada Kelompok II menggunakan uji beda yaitu paired sample t-test. Dari hasil perhitungan didapatkan nilai $\mathrm{p}=0,0001(\mathrm{p}<$ $0,05)$ yang berarti ada perbedaan yang bermakna dari peningkatan daya tahan kardiorespirasi sebelum dan setelah intervensi High-intensity Interval Training rasio work-torest $1: 1$ pada pelari komunitas.

Selanjutnya persentase peningkatan daya tahan kardiorespirasi pelari komunitas pada kedua kelompok dapat disajikan pada Tabel 4. Berdasarkan persentase peningkatan daya tahan kardiorespirasi pelari komunitas pada Tabel 5.5 menunjukkan bahwa persentase peningkatan daya tahan kardiorespirasi pada Kelompok II lebih besar daripada Kelompok I.

Tabel 4.

Persentase Peningkatan daya tahan kardiorespirasi pada pelari komunitas setelah intervensi

\begin{tabular}{|c|c|c|c|c|}
\hline \multirow{2}{*}{$\begin{array}{c}\text { Kelo } \\
\text { mpo } \\
\text { k }\end{array}$} & \multicolumn{4}{|c|}{ Hasil Analisis } \\
\hline & $\begin{array}{c}\mathrm{VO}_{2} \max \\
\text { Awal }\end{array}$ & $\begin{array}{c}\mathrm{VO}_{2} \max \\
\text { Akhir }\end{array}$ & $\begin{array}{c}\text { Beda } \\
\text { Nilai } \\
\mathrm{VO}_{2} \\
\max \end{array}$ & $\begin{array}{c}\text { Persentase } \\
\text { beda nilai } \\
\mathrm{VO}_{2} \max \\
(\%)\end{array}$ \\
\hline I & 38,80 & 43,13 & 4,33 & $11,16 \%$ \\
\hline II & 35,77 & 42,22 & 6,45 & $18,03 \%$ \\
\hline
\end{tabular}

\section{PEMBAHASAN}

\section{Peningkatan daya tahan kardiorespirasi pada High-intensity Interval Training rasio work-to-rest 2 : 1}

Berdasarkan hasil uji Paired Sample TTest pada kelompok I, didapatkan nilai $\mathrm{p}=$ $0,002(\mathrm{p}<0,05)$ yang berarti ada perbedaan yang bermakna pada nilai $\mathrm{VO}_{2}$ max sebelum dan sesudah intervensi High-intensity Interval Training rasio work-to-rest $2: 1$. Hal tersebut menunjukkan bahwa intervensi pada kelompok I (High-intensity Interval Training rasio work-to-rest 2 : 1) memberikan peningkatan yang bermakna terhadap daya tahan kardiorespirasi. Latihan HIIT dengan rasio 2:1 (4 menit lari dengan 85-90\% HR, 2 menit active rest dengan 60-65\% HR) pelari akan melakukan latihan yang lebih lama namun mendapatkan pemulihan yang lebih singkat. Hal ini memungkinkan kebutuhan oksigen yang lebih banyak namun memungkinkan pembersihan asam laktat lebih singkat.

Secara umum tujuan HIIT adalah untuk meningkatkan kinerja fisiologis, psikologis, dan metabolisme dengan memaksimalkan waktu yang dihabiskan untuk melakukan latihan intensitas tinggi. ${ }^{5}$ Meningkatkan daya tahan kardiorespirasi sangat bergantung pada fungsi yang efektif dan integrasi sistem kardiovaskular dan pernapasan. Daya tahan kardiorespirasi bergantung pada kemampuan tubuh untuk membawa (yaitu, curah jantung) dan menggunakan oksigen. Salah satu tanda adaptasi pada latihan HIIT adalah meningkatnya curah jantung yang hasilnya terutama dari peningkatan stroke volume. Curah jantung maksimal sangat berkaitan dengan latihan maksimal, jadi semakin tinggi curah jantung, semakin tinggi daya tahan kardiorespirasinya. ${ }^{4}$

Selama HIIT, kemampuan untuk mempertahankan latihan yang adekuat tanpa gangguan homeostasis yang menyebabkan kelelahan dini dikendalikan oleh durasi interval atau durasi periode rest. Rest adalah komponen penting dari latihan selama sesi latihan berulang, tidak hanya antara sesi latihan. Hasil dari penelitian Laurent dkk pada tahun 2014 mendukung gagasan bahwa rasio work-to-rest 2:1, dalam hal ini latihan 4 menit dengan pemulihan 2 menit, selama HIIT diperpanjang cenderung menghasilkan stimulus latihan yang tepat dan dianggap tidak sulit. $^{5}$ 
Peningkatan daya tahan kardiorespirasi pada High-intensity Interval Training rasio work-to-rest 1 : 1

Berdasarkan hasil uji Paired Sample TTest pada kelompok II, didapatkan nilai $\mathrm{p}=$ $0,0001(\mathrm{p}<0,05)$ yang berarti ada perbedaan yang bermakna pada nilai $\mathrm{VO}_{2}$ max sebelum dan sesudah intervensi High-intensity Interval Training rasio work-to-rest $1: 1$. Hal tersebut menunjukkan bahwa intervensi pada kelompok I (High-intensity Interval Training rasio work-to-rest $1:$ 1) memberikan peningkatan yang bermakna terhadap daya tahan kardiorespirasi.

Latihan HIIT dengan rasio 1:1 (3 menit lari dengan $85-90 \% \mathrm{HR}, 3$ menit active rest dengan $60-65 \%$ HR) pelari akan melakukan latihan yang sama durasinya dengan rest. Hal ini memungkinkan ini memungkinkan seseorang akan melakukan pemulihan lebih lama sehingga memungkinkan pembersihan asam laktat pada darah lebih lama.

Menyesuaikan rasio work-to-rest dengan benar sangat penting untuk memungkinkan seorang pelari menyelesaikan sesi latihan yang ditentukan. ${ }^{3}$ HIIT baiknya berlangsung selama 3 sampai 5 menit, dengan periode istirahat 1:1, latihan HIIT dapat meningkatkan daya tahan kardiorespirasi terutama melalui peningkatan ambang laktat dan meningkatkan kemampuan tubuh untuk membersihkan laktat dari aliran darah. Sehingga pelari akan dapat melanjutkan sesi interval selanjutnya sampai intensitas latihan selesai dan target heartrate dapat tercapai.

Perbedaan Pengaruh High-intensity Interval Training rasio work-to-rest 2 : 1 dan 1 : 1 dalam meningkatkan daya tahan kardiorespirasi pada pelari komunitas.

Pada penelitian ini terdapat 2 kelompok perlakuan yang masing-masing kelompok terdiri dari 11 sampel, di mana kedua kelompok tersebut memiliki karakteristik subjek yang sama. Kelompok I diberikan intervensi High-intensity Interval Training rasio work-to-rest $2: 1$ sedangkan Kelompok II diberikan intervensi Highintensity Interval Training rasio work-to-rest 1
: 1. Didapatkan hasil uji beda post test kelompok I dan II yaitu $p=0,579(p>0,05)$. Hal ini berarti tidak ada perbedaan yang bermakna pada intervensi High-intensity Interval Training rasio work-to-rest $2: 1$ dengan High-intensity Interval Training rasio work-to-rest $1: 1$ terhadap peningkatan daya tahan kardiorespirasi, sehingga High-intensity Interval Training rasio work-to-rest $2: 1 \&$ High-intensity Interval Training rasio work-torest 1 : 1 sama baiknya dalam meningkatkan daya tahan kardiorespirasi. Hal ini disebabkan karena kondisi pelari yang sudah terlatih dan latihan yang kurang overload untuk pelari, sehingga hasil dari kedua perlakuan sama.

Pada penelitian ini masing-masing HIIT memiliki rerata intensitas selama 30 menit, HIIT rasio work-to-rest 2:1 memiliki volume latihan interval selama 16 menit sedangkan HIIT rasio work-to-rest 1:1 memiliki volume latihan selama 12 menit. Ketika HIIT dengan rasio 1:1 (3 menit lari dengan $85-90 \%$ HR, 3 menit active rest dengan 60-65\% HR) seorang pelari akan mendapatkan pemulihan yang lebih lama dibandingkan dengan rasio 2:1 (4 menit lari dengan 85-90\% $\mathrm{HR}, 2$ menit active rest dengan 60-65\% HR). Active rest sebaiknya dilakukan dalam waktu 3 - 4 menit ketika melakukan intensitas submaksimal (60-80\% denyut jantung maksimal) untuk mempertahankan latihan intensitas tinggi ketika interval ${ }^{7}$, namun ada pula menurut Morrison pada tahun 2017 untuk melakukan latihan intensitas sedang dalam hal ini active rest pada penelitian ini, yaitu 2-3 menit. ${ }^{8}$

HIIT dengan rasio 2:1, tubuh akan mendapatkan pemulihan yang lebih singkat dan latihan yang lebih panjang sehingga kelelahan akan lebih cepat terjadi ketika melakukan latihan interval. Hal ini berhubungan dengan rendahnya oxygen uptake $\left(\mathrm{VO}_{2}\right)$ ketika periode rest yang memungkinkan defisit $\mathrm{O}_{2}$ ketika latihan interval. Memperpanjang durasi interval pada latihan HIIT tanpa disertai dengan durasi istirahat jelas akan meningkatkan kontribusi glikolisis anaerobik, selama lebih banyak latihan yang diselesaikan dalam periode tertentu. Hasil dari penelitian Laurent dkk pada tahun 2014 menunjukkan adanya peningkatan kontribusi 
energi glikolisis anaerobik ketika meningkatkan durasi interval latihan (2 menit vs 1 menit lari, rasio work-to-rest $1: 1){ }^{5}$ Terdapat penelitian sebelumnya yang meneliti tentang tingkat asam laktat ketika memanipulasi rest dalam interval, lari 4-menit dengan intensitas interval $83-85 \% \quad \mathrm{VO}_{2} \max$, dengan mengurangi rest intervalnya dari 4menit ke 1-menit, hasil dari penelitian tersebut tidak menunjukkan adanya pengaruh pada pelari yang terlatih. ${ }^{7}$

\section{KETERBATASAN PENELITIAN}

Pada penelitian ini terdapat keterbatasan dalam beberapa hal yaitu :

1. Peneliti tidak dapat mengontrol aktivitas pelari yang dapat mempengaruhi kelelahan saat dilakukan intervensi.

2. Instrumen penelitian untuk mengukur heartrate masih bervariasi sehingga dapat memberikan akurasi pengukuran yang berbeda-beda.

3. Lapangan yang digunakan berbeda-beda baik pada kelompok I dan kelompok II.

\section{DAFTAR PUSTAKA}

1. Ilmiyanto, F., Budiwanto, S. 2017. Perbedaan Pengaruh antara Metode Latihan Fartlek dan Metode Latihan Continuous Tempo Running Terhadap Peningkatan Daya Tahan Kardiovaskuler Peserta Latihan Lari Jarak Jauh. Indonesia Performance Journal. Vol.1, No.2

2. Predel, H.G. 2014. Marathon run: Cardiovascular Adaptation and Cardiovascular Risk. European Heart Journal. Vol.35, No.44: 3091-3096.

3. Cavar, M., Marsic, T., Corluka, M., Culjak, Z., Zovko, I., Cerkes., Muller, A., Tschakert, G. Hofmann, P. 2018. Effects of 6 Weeks of Different HighIntensity Interval and Moderate Continuous Training On Aerobic and Anaerobic Performance. $J$ Strength Cond Res. Vol.33, No.1: 44-56.
4. Coburn, J.W., Malek, M.H. 2012. NCSA's Essentials Personal Training. United States: Human Kinetics.

5. Laurent,C.M., Vervaecke, L.S., Kutz, M.R., Green, J.M. 2014. Sex-Specific Responses to Self-Paced, HighIntensity Interval Training With Variable Recovery Periods. J Strength Cond Res. Vol.28, No.4: 920-7.

6. Gosselin, L.E., Kozlowski, K.F., DeVinney-Boymel, L., Hambridge, C. 2012. Metabolic Response of Different High-Intensity Aerobic Interval Exercise Protocols. J Strength Cond Res. Vol.26, No.10:2866-2871

7. Buchheit, M., Laursen, P.B. 2013. High-Intensity Interval Training, Solutions to the Programming Puzzle Part II: Anaerobic Energy, Neuromuscular Load and Practical Applications. Switzerland: Springer International Publishing.

8. Morrison, S., Ward, P., duManoir, G.R. 2017. Energy System Development and Load Management through the Rehabilitation and Return to Play Process. Int J Sports Phys Ther. Vol.12, No.4:697. 